\title{
Density Functional and Hartree-Fock Calculations on the Cyclopropane Ring Intermediates Involved in the Zeolite-Catalyzed Skeletal Isomerization of Hydrocarbons and in the Carbon Isotope Scrambling in 2-Propyl Cation
}

\author{
M. V. Frash, ${ }^{*} \dagger$ V. B. Kazansky, ${ }^{\dagger}$ A. M. Rigby, ${ }^{\ddagger}$ and R. A. van Santen ${ }^{\S}$ \\ Zelinsky Institute of Organic Chemistry, Russian Academy of Sciences, Moscow B-334, Russia, Shell Research \\ and Technology Centre Amsterdam, P.O. Box 3800, 1030 BN Amsterdam, The Netherlands, and Eindhoven \\ University of Technology, P.O. Box 513, Eindhoven, The Netherlands
}

Received: December 11, 1996; In Final Form: March 19, $1997^{\otimes}$

\begin{abstract}
Quantum-chemical calculations were carried out on the mechanism of the zeolite-catalyzed hydrocarbon skeletal isomerization via the cyclopropane ring intermediates. According to the B3LYP/6-31G* calculations, formation of cyclopropane from surface alkoxy species in zeolites occurs via a transition state whose hydrocarbon part resembles a corner-protonated cyclopropane (corner-PCP) ring. Two conformations of the transition state found differ in the orientation of the PCP portion with respect to the acid site. The activation energy for the cyclopropane ring closure reaction is found to be rather sensitive to the use of planar symmetry constraints and to the level of calculations and less sensitive to the level of the geometry optimization. Calculations on the mechanism of the carbon isotope scrambling in the free 2-propyl cation were also performed, at several theory levels up to the Gaussian-2 model. The relatively stable intermediates of this superacid-catalyzed reaction are carbocations, in contrast to the zeolite-catalyzed isotope scrambling where the relatively stable intermediates are surface alkoxy species with the corner-protonated cyclopropane as a high-energy transition state.
\end{abstract}

\section{Introduction}

Skeletal isomerization of carbenium ions is an important elementary reaction step in solid acid catalyzed transformations of hydrocarbons. ${ }^{1,2}$ Besides being the major step in some commercial processes, e.g. conversion of $n$-butenes to iso-butene and $n$-alkane hydroisomerization, this reaction influences the product distribution of the cracking and alkylation processes. Extensive experimental studies of skeletal isomerization have been performed, ${ }^{3-19}$ and it has been found that this reaction proceeds via either a monomolecular or bimolecular (dimerization/cracking) mechanism.

The monomolecular skeletal isomerization is found to be more common. Indeed, $n$-pentane and larger hydrocarbons isomerize via the monomolecular path both on zeolites and on sulfated zirconia. ${ }^{4,6,7}$ Isomerization of $n$-butenes might follow either a monomolecular or bimolecular path, dependent on the type of the catalyst and on the reaction conditions. The bimolecular mechanism is found to be predominant on a number of zeolites, ${ }^{7-13}$ while on the sulfated zirconia both the monomolecular ${ }^{7,14}$ and bimolecular ${ }^{15,16}$ mechanisms were reported to be more important. Isomerization of $n$-butenes on the H/FER zeolite represents an interesting example: the bimolecular mechanism occurs on the fresh zeolite samples, but on the aged catalyst the monomolecular process becomes predominant, resulting in much better selectivity toward iso-butene. ${ }^{18,19}$

The monomolecular isomerization in turn might occur in two ways: via the one-step methyl shift or via the "protonated cyclopropane" mechanism. It is difficult to distinguish between these two cases on the grounds of the experimental data, but arguments of Olah's carbocation theory ${ }^{20}$ have provided some insight on this subject. Thus, isomerization of linear hydro-

\footnotetext{
$\dagger$ Russian Academy of Sciences.

¥ Shell Research and Technology Centre Amsterdam.

$\S$ Eindhoven University of Technology.

${ }^{\otimes}$ Abstract published in Advance ACS Abstracts, May 1, 1997.
}

carbons via the one-step methyl shift is unlikely as this inevitably includes intermediate formation of the unstable primary carbenium ions. In contrast, the protonated cyclopropane path for isomerization of pentane and larger linear hydrocarbons includes only the relatively stable secondary and tertiary carbenium ions. Therefore this mechanism has been initially suggested by Brouwer et al. ${ }^{21,22}$ for skeletal isomerization in liquid superacids and later by Chevalier et al. ${ }^{3}$ and by Weitkamp ${ }^{4}$ for isomerization in zeolites.

Besides experimental techniques, quantum-chemical calculations are nowadays being used in studies of the reactions catalyzed by solid acids for more detailed understanding of their molecular mechanisms. ${ }^{23-25}$ Recently calculations on a wide range of commercially important hydrocarbon reactions on zeolites including $\beta$-scission and skeletal isomerization have been reported. ${ }^{26}$ However those calculations ${ }^{26}$ were performed at a modest level (MP2/6-31G*//HF/3-21G) and with symmetry constraints imposed on the geometries of the species involved. Thus the issues considered in that work deserve further and more detailed investigation.

The present paper is devoted to the more detailed study of the cyclopropane ring closure/opening reaction. This reaction is chosen both due to its importance as an essential part of the mechanism of skeletal isomerization and due to its sensitivity to potential methodological errors. Indeed, the protonated cyclopropane (PCP) fragment is a part of the transition state for this reaction, and it is known that computed relative energies of the free PCP isomers are very sensitive to the level of calculations. ${ }^{27}$ Here we analyze how the description of the cyclopropane ring closure/opening reaction mechanism depends on the use of the symmetry constraints and on the introduction of the electron correlation effects in the geometry optimization calculations.

A comparison will also be made between the adsorbed PCP moiety in the zeolite-catalyzed reactions of hydrocarbons and the free PCP moiety in the superacid-catalyzed reactions. The 


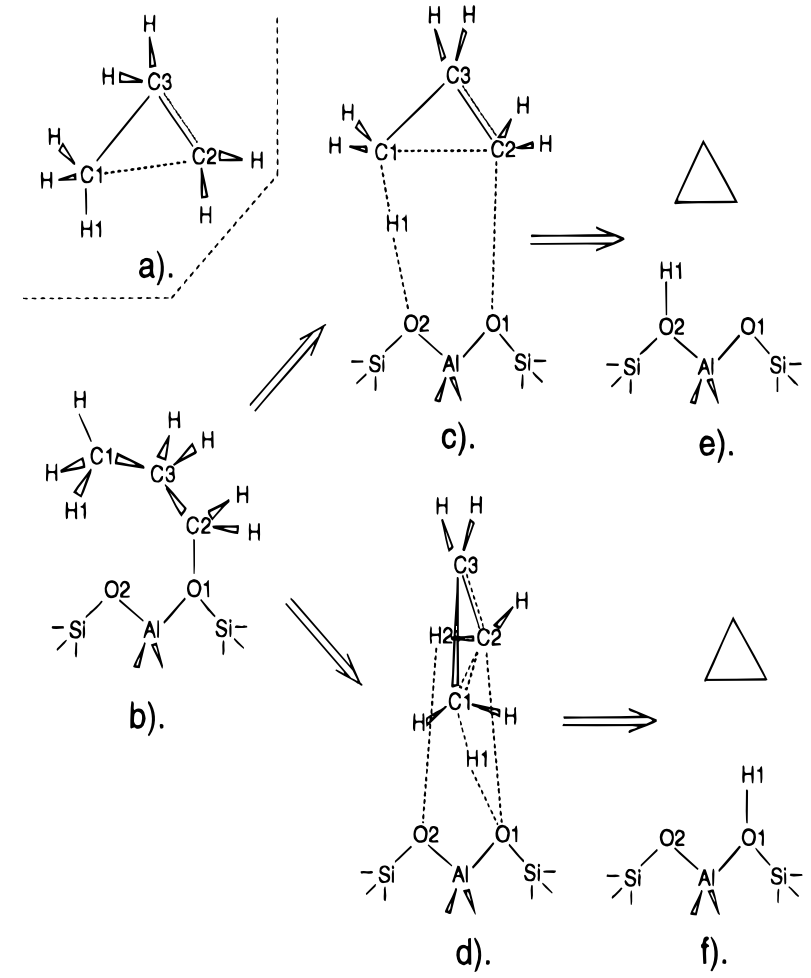

Figure 1. Cyclopropane ring closure in zeolites: a, free corner-PCP (given for comparison); b, surface prop-1-oxy; c, the near-in-plane TS; $\mathrm{d}$, the out-of-plane TS; e and f, free Brønsted acid site plus cyclopropane. The most important interatomic distances and charge parameters are given in Tables 2 and 3.

relation between mechanisms and active intermediates of homogeneous and heterogeneous acid catalysis is a very interesting problem. Schemes based on reactions of free carbocations established for the liquid superacid systems ${ }^{20}$ are now frequently used for description of the solid acid catalyzed transformations of hydrocarbons. However recently it has been shown that such schemes, although in good agreement with kinetic regularities and final product distributions, require some simplification of the solid acid catalyzed reaction mechanisms. ${ }^{28,29}$ Indeed, the results of quantum-chemical calculations together with the IR and NMR data indicated that the relatively stable intermediates of the zeolite-catalyzed hydrocarbon reactions are covalent surface esters, ${ }^{30-33}$ while carbocations represent high-energy activated complexes and/or transition states. ${ }^{26,33-38}$ The zeolite-catalyzed skeletal isomerization also starts from covalent surface alkoxy species, ${ }^{26}$ while the ionic protonated cyclopropane species are high-energy transition states for cyclopropane ring closure/opening. In contrast, the liquid superacid systems contain relatively stable secondary and tertiary carbenium ions which undergo skeletal isomerization.

\section{Models and Computational Details}

All the computations were performed with the Gaussian 94 program. ${ }^{39}$ The natural population analysis (NPA) based charges ${ }^{40}$ were computed using the natural bond orbital package of the Gaussian 94 program. ${ }^{41}$

The catalytically active Brønsted acid sites of zeolites were modeled by the cluster $\mathrm{H}_{3} \mathrm{Si}(\mathrm{OH}) \mathrm{AlH}_{2}\left(\mathrm{OSiH}_{3}\right)$ shown in Figure 1e. The cluster approach has proven to be quite useful in studies of the mechanisms of zeolite-catalyzed reactions (see ref 1724 in the paper of Viruela-Martin et al., ${ }^{36}$ reviews, ${ }^{23-25}$ and recent works, e.g. of Evleth et al. ${ }^{42}$ and Blaszkowski et al. ${ }^{43}$ ). A number of authors have tested the effects of the cluster size ${ }^{42}$ and of acid strength modification ${ }^{26,37,44}$ on the description of
TABLE 1: Total Energies, Imaginary Frequencies, and Zero-Point Energies of the Reagent, Products, and Two Transition State Conformations for Cyclopropane Ring Closure As Calculated at the B3LYP/6-31G* Level

\begin{tabular}{lrcc}
\hline \multicolumn{1}{c}{ structure } & total energy, au & $\begin{array}{c}\text { imaginary } \\
\text { frequency, } \\
\mathrm{cm}^{-1}\end{array}$ & $\begin{array}{c}\text { zero-point } \\
\text { energy, } \\
\mathrm{kcal} / \mathrm{mol}\end{array}$ \\
\hline surface prop-1-oxy & -1095.341916 & $32^{a}$ & 107.2 \\
free cluster & -977.406001 & $43^{a}$ & 53.0 \\
cyclopropane & -118.195410 & & 51.3 \\
TS near-in-plane & -1095.247008 & $149^{b} ; 34^{a}$ & 104.5 \\
TS out-of-plane & -1095.249507 & $300^{b}$ & 104.1
\end{tabular}

${ }^{a}$ Imaginary frequency caused by the constraint on two dihedrals in the cluster (see Models and Computational Details). ${ }^{b}$ Imaginary frequency associated with the reaction coordinate.

hydrocarbon reactions such as chemisorption of alkenes, hydrogen-deuterium exchange, and protolytic cracking. They observed some changes in the calculated activation energies, but the reaction mechanisms remained unchanged. Therefore effects of the cluster model changes were not considered in the present work.

Geometries of the free site, surface prop-1-oxy, and the transition state for cyclopropane ring closure were optimized keeping the aluminum, both silicon, and both oxygen atoms of the cluster in one plane. Such constraint suppresses two soft modes not present in a real zeolite, and thus makes the optimization much faster, while its effect on the activation energies is negligible (less than $1.0 \mathrm{kcal} / \mathrm{mol}$ as tested at the MP2(FC)/6-31G*//3-21G level). No other geometry constraints were imposed.

Nonlocal density functional (DFT) calculations using the B3LYP method (the Becke's three-parameter hybrid exchange ${ }^{44}$ with the Lee-Parr-Yang correlation ${ }^{45}$ functional) were applied for the intermediates and the transition state of the zeolitecatalyzed cyclopropane ring closure reaction. The standard Pople's 6-31G* basis $\operatorname{set}^{27}$ was used. The calculated total energies, zero-point energies, and imaginary frequencies of the relevant structures are given in Table 1. The DFT calculations give geometries optimized with the electron correlation effects included, which might be particularly important for the transition state containing the nonclassical protonated cyclopropane ring. Indeed, it has been found that the geometry optimization at a correlated level is necessary for description of a number of free nonclassical carbocations. ${ }^{27,47-51}$ However for the purpose of comparison we performed geometry optimization at the Hartree-Fock levels $\left(\mathrm{HF} / 6-31 \mathrm{G}^{*}\right.$ and $\left.\mathrm{HF} / 3-21 \mathrm{G}\right)$ and calculated HF/3-21G, HF/6-31G*, MP2(FC)/6-31G*, and B3LYP/6-31G* final energies for all three HF/3-21G, HF/6-31G*, and B3LYP/ 6-31G* optimized geometries.

Calculations on the free $\mathrm{C}_{3} \mathrm{H}_{7}{ }^{+}$isomers (which are computationally much less demanding than calculations on the zeolitecatalyzed reaction due to both the smaller number of atoms involved and a less complex potential energy surface) have been performed at several levels: the B3LYP/6-31G*, BLYP/6$31 \mathrm{G}^{* 52,46}$, B3P86/6-31G ${ }^{* 45,53}$, MP2(FU)/6-31G*, and Gaussian$2 .^{54}$

Transition state (TS) structures were characterized by analyzing the (analytically calculated) vibrational normal modes and by a local minimum search (after a small distortion of a TS in the reaction coordinate direction) to reach reagents and products. The computed relative energies of all species involved were corrected for the zero-point energies obtained from the vibrational modes calculations. Unscaled frequencies were used for this, except for the Gaussian-2 calculations where, in accordance with the definition of the model, ${ }^{54}$ the HF/6-31G* frequencies scaled with a factor of 0.8929 were used. 
TABLE 2: The Most Important Interatomic Distances (in Angstroms) in the Free Corner-Protonated Cyclopropane Moiety and in the Transition State for Cyclopropane Ring Closure on the Zeolite Brønsted Acid Site, As Calculated at the B3LYP/ 6-31G* (Default), HF/6-31G*, and HF/3-21G Levels

\begin{tabular}{lcccccrrr}
\hline \multicolumn{1}{c}{ structure } & $\mathrm{C} 1-\mathrm{C} 2$ & $\mathrm{C} 1-\mathrm{C} 3$ & $\mathrm{C} 2-\mathrm{C} 3$ & $\mathrm{C} 1-\mathrm{H} 1$ & $\mathrm{O} 1-\mathrm{H} 1$ & $\mathrm{O} 2-\mathrm{H} 2$ & $\mathrm{O} 1-\mathrm{C} 2$ & $\mathrm{O} 2-\mathrm{C} 2$ \\
\hline free corner-PCP & 1.841 & 1.727 & 1.393 & 1.104 & & & \\
near-in-plane TS (1c) & 1.885 & 1.635 & 1.415 & 1.121 & 2.233 & 2.759 & 2.583 \\
out-of-plane TS (1d) & 2.148 & 1.641 & 1.417 & 1.096 & 2.189 & 1.891 & 2.631 \\
out-of-plane TS (1d), HF/6-31G* optimized & 1.727 & 1.551 & 1.431 & 1.178 & 1.769 & 2.182 & 2.895 & 3.003 \\
out-of-plane TS (1d), HF/3-21G optimized & 1.853 & 1.695 & 1.402 & 1.173 & 1.583 & 1.803 & 2.914 & 2.848
\end{tabular}

TABLE 3: The Most Important NPA and Mulliken Charges (in Multiples of the Electron Charge) in the Free Corner-Protonated Cyclopropane Moiety and in the Transition State for Cyclopropane Ring Closure on the Zeolite Brønsted Acid Site, as Calculated at the B3LYP/6-31G* level $^{a}$

\begin{tabular}{|c|c|c|c|c|c|c|c|c|}
\hline \multirow[b]{2}{*}{ structure } & \multicolumn{4}{|c|}{ NPA charges } & \multicolumn{4}{|c|}{ Mulliken charges } \\
\hline & Q1 & Q2 & Q3 & QSUM & Q1 & Q2 & Q3 & $\overline{\text { QSUM }}$ \\
\hline free corner-PCP & +0.332 & +0.399 & +0.268 & +1.0 & +0.338 & +0.365 & +0.297 & +1.0 \\
\hline near-in-plane TS (1c) & +0.286 & +0.507 & +0.115 & +0.908 & +0.245 & +0.418 & +0.171 & +0.834 \\
\hline out-of-plane TS (1d) & +0.225 & +0.609 & +0.032 & +0.866 & +0.219 & +0.451 & +0.120 & +0.790 \\
\hline
\end{tabular}

${ }^{a} \mathrm{Q} 1$ represents the sum of the atomic charges on the methyl group with the $\mathrm{C} 1$ carbon (see Figure 1), Q2 and Q3 represent the sum of the atomic charges on the methylene groups with the C2 and C3 carbons, respectively, and QSUM = Q1 + Q2 + Q3.

\section{Results and Discussion}

3.1. The Cyclopropane Ring Closure Reaction on the Zeolite Brønsted Acid Sites. The mechanism of the zeolitecatalyzed hydrocarbon skeletal isomerization via substituted cyclopropanes has been considered earlier by Rigby et al. ${ }^{26}$ Starting from an alkoxy species (a hydrocarbon fragment covalently bound to one of the oxygen atoms of the acid site), a substituted cyclopropane is formed with donation of a proton to the zeolite to form a free Brønsted acid site. When the ring is reopened by protonation a different bond can then be broken, leading to isomerization.

Calculations in the cited work ${ }^{26}$ were performed at the MP2(FU)/6-31G*//3-21G level. The planar symmetry constarints were imposed on all species. Due to those constraints only one conformation of the TS for the cyclopropane ring closure could be found. The activation energy was computed to be $77 \mathrm{kcal} /$ mol.

Calculations on the cyclopropane ring closure were reproduced at the B3LYP/6-31G* level without symmetry constraints, and two conformations of the transition state were found. Both these conformations (see parts $\mathrm{c}$ and d of Figure 1) represent a complex of the corner-protonated cyclopropane (corner-PCP) species and the zeolite cluster, similar to the TS found earlier. ${ }^{26}$ The difference between the two conformations lies in the different orientation of the PCP portion with respect to the cluster.

A comparison between the geometry and charge parameters of the adsorbed PCP moieties with those of the free cornerPCP is presented in Tables 2 and 3 . In the free PCP, the $\mathrm{C} 1-$ $\mathrm{C} 2$ and $\mathrm{C} 1-\mathrm{C} 3$ bonds adjacent to the methyl group (1.841 and $1.727 \AA$ ) are longer than a single carbon-carbon bond, whereas the length of the $\mathrm{C} 2-\mathrm{C} 3$ bond $(1.393 \AA)$ is intermediate between a single and a double bond. According to Wiberg and Kass ${ }^{55}$ this suggests that the corner-PCP species may be considered as a complex of ethene with the methyl cation formed by charge transfer from the occupied $\pi$-orbital of ethene to the lowest unoccupied $\sigma$-orbital of the methyl cation. The amount of the charge transfer from ethene to the methyl cation is significant, and only $0.332 \mathrm{e}$ of the total positive charge is located on the methyl fragment, the remaining 0.668 e being located on the ethene fragment (here and below we describe the NPA charges as more reliable, but the Mulliken charges exhibit similar tendencies). The NPA analysis of bonding in the free cornerPCP shows three carbon core orbitals, seven two-centered carbon-hydrogen bonds, one two-centered bond between the
$\mathrm{C} 2$ and $\mathrm{C} 3$ carbons, and the nonclassical three-centered bond formed by almost equal contributions from all three carbons: $38 \%$ from $\mathrm{C} 1,28 \%$ from $\mathrm{C} 2,35 \%$ from $\mathrm{C} 3$.

When the PCP is adsorbed on the zeolite and constitutes a part of a transition state, the interaction with the catalytic site causes significant changes in the PCP geometry and charge parameters. This holds for both the $1 \mathrm{c}$ and $1 \mathrm{~d}$ conformations of the transition state. Polarization of the PCP portion by the negatively charged cluster causes a shift of the positive charge to the methylene group containing the $\mathrm{C} 2$ carbon. This group has a positive charge of 0.609 or $0.507 \mathrm{e}$ in the transition states versus $0.399 \mathrm{e}$ in the free PCP. The nonclassical three-centered bond is being shifted away from the $\mathrm{C} 2$ carbon toward the $\mathrm{C} 1$ and $\mathrm{C} 3$ atoms. Indeed, contributions of the $\mathrm{C} 2$ atom to this bond significantly decrease in comparison with those in the free PCP: $22 \%$ in the TS (1c) and $18 \%$ in TS (1d) versus $28 \%$ in the free corner-PCP. This is in line with the fact that the $\mathrm{C} 1-$ $\mathrm{C} 2$ and $\mathrm{C} 2-\mathrm{C} 3$ distances become longer while the $\mathrm{C} 1-\mathrm{C} 3$ distance becomes shorter. Finally, it can be seen that the total charge on the adsorbed PCP is smaller than $1 \mathrm{e}$, likely due to the charge transfer from the negative cluster. These changes in the geometry and charge parameters indicate that the adsorbed PCP involved in the zeolite-catalyzed skeletal isomerization resembles but is not equivalent to the free PCP involved in the skeletal isomerization catalyzed by liquid superacids.

The two conformations of the TS for cyclopropane ring closure and reaction paths are now to be considered. The first "near-in-plane" conformation (Figure 1c) has all three carbon atoms located close to the $\mathrm{O} 1-\mathrm{Al}-\mathrm{O} 2$ plane of the cluster: their deviations from this plane are within $0.15-0.40 \AA$, and the angle between the $\mathrm{O} 1-\mathrm{Al}-\mathrm{O} 2$ and $\mathrm{C} 1-\mathrm{C} 2-\mathrm{C} 3$ planes is only $7.5^{\circ}$. This conformation resembles the TS found by Rigby et al. ${ }^{26}$ with the planar symmetry constraints; however, the terminal hydrogens of the cluster in 1c deviate sufficiently from the planar symmetry, and this is likely to reduce the steric hindrances. The corresponding reaction path starts from the elongation of the $\mathrm{O} 2-\mathrm{C} 2$ bond in the surface prop-1-oxy; after that a new $\mathrm{C} 2-\mathrm{C} 1$ bond is being formed while the $\mathrm{H} 1$ hydrogen is being transferred to the surface $\mathrm{O} 1$ oxygen.

The second "out-of-plane" conformation of the TS (Figure 1d) has a rather large angle $\left(79.4^{\circ}\right)$ between the $\mathrm{C} 1-\mathrm{C} 2-\mathrm{C} 3$ plane and the $\mathrm{O} 1-\mathrm{Al}-\mathrm{O} 2$ plane. The reaction path associated with this TS conformation also involves the elongation of the $\mathrm{O} 1-\mathrm{C} 2$ bond in the surface prop-1-oxy, formation of the new $\mathrm{C} 2-\mathrm{C} 1$ bond, and transfer of the $\mathrm{H} 1$ hydrogen to the surface 
TABLE 4: Activation Energies (in kcal/mol; Including Corrections for the Zero-Point Energies (ZPE)) for the Cyclopropane Ring Closure Reaction As Found at Different Levels of the Geometry Optimization and Final Energy Calculation

\begin{tabular}{lccccc}
\hline & \multicolumn{4}{c}{ level of the final energy calculation } \\
\cline { 2 - 6 } level of the geometry optimization & HF/3-21G & HF/6-31G* & MP2(FC)/6-31G* & B3LYP/6-31G* & ZPE contribution \\
\hline HF/3-21G & 67.0 & 59.5 & 51.2 & 49.2 & -4.2 \\
HF/6-31G* & 73.3 & 56.0 & 46.9 & 47.8 & -3.6 \\
B3LYP/6-31G* & 67.6 & 57.6 & 59.3 & 54.9
\end{tabular}

O1 oxygen. However in this path the hydrogen atom is being transferred to the same $\mathrm{O} 1$ oxygen which was bound to the $\mathrm{C} 2$ carbon in the initial state. The $\mathrm{O} 2$ oxygen is not bound to any carbons or hydrogens in both the initial and the final states, but the strong hydrogen bond (1.891 $\AA$ ) formed in the TS (1d) between this oxygen and the $\mathrm{H} 2$ hydrogen is likely to stabilize the TS and thus reduce the activation energy.

Since cyclopropane is a strained molecule, its formation from surface alkoxy is rather highly endoergic: $+22.7 \mathrm{kcal} / \mathrm{mol}$ at the B3LYP/6-31G* level. Note that after reorientation this ring is being reopened and a new alkoxy species is being formed, thus the overall skeletal isomerization process appears to be almost thermoneutral. The B3LYP/6-31G* activation energy for cyclopropane ring closure is slightly lower if the reaction proceeds via the out-of-plane TS (Figure 1d) rather than via the near-in-plane one (1c): 54.9 versus $56.9 \mathrm{kcal} / \mathrm{mol}$. This is probably caused by the slightly lower total positive charge on the PCP in the out-of-plane conformation (see Table 3).

Both the above mentioned B3LYP/6-31G* activation energies (54.9 and $56.9 \mathrm{kcal} / \mathrm{mol})$ are significantly lower than that found by Rigby et al. ${ }^{26}$ at the MP2/6-31G*//3-21G level and with planar symmetry constraints $(77 \mathrm{kcal} / \mathrm{mol})$. In part this difference is caused by the zero-point corrections taken into account in the present work (about $3 \mathrm{kcal} / \mathrm{mol}$, see Table 4). The remaining $18-20 \mathrm{kcal} / \mathrm{mol}$ of difference are caused mostly by the planar symmetry constraints imposed in the cited work, ${ }^{26}$ since our calculations at the MP2/6-31G*//3-21G level without planar symmetry constraints (see Table 4 ) yield the activation energy of $51.2 \mathrm{kcal} / \mathrm{mol}$ which is again lower than that from the sited work $^{26}$ and close to the B3LYP/6-31G* values.

The calculated activation energy for cyclopropane ring closure is to be compared with the available experimental activation energies for skeletal isomerization in zeolites. The activation energies of 26.7 and $13.1 \mathrm{kcal} / \mathrm{mol}$ (in different temperature ranges) were reported for n-pentane isomerization on $\mathrm{Pt} / \mathrm{H}-\mathrm{Mor}^{56}$ and were of about $30 \mathrm{kcal} / \mathrm{mol}$ for $n$-hexane isomerization on Pt/H-ZSM-5 and Pt/H-Mor. ${ }^{57}$ Thus the activation energies computed at the MP2 or B3LYP correlated levels (47-59 kcal/ mol, see Table 4) without symmetry constraints are closer to the experimental data than the value found with symmetry constraints $^{26}(77 \mathrm{kcal} / \mathrm{mol})$ but are still too high. The remaining discrepancy might have the following reasons: (i) the experimental data correspond to hydrocarbons with more than three carbon atoms and the "C3 ring" transition states for such hydrocarbons are stabilized by the extra alkyl groups, ${ }^{58}$ thus leading to lower activation energies than that for the unsubstituted cyclopropane; (ii) the acid strength of the cluster used in the calculations is lower than that of the real zeolite $;{ }^{59}$ and (iii) the cluster calculations do not take into account the Coulomb interaction between the positive hydrocarbon portion of the transition state and the negative oxygen atoms situated in the zeolite cage but not connected with the aluminum atom. ${ }^{60}$

Finally one can compare the activation energies found with different combinations of the geometry optimization and final energy calculation levels (see Table 4). Only the out-of-plane conformation of the TS was located at the HF/6-31G* and HF/ 3-21G levels (Figure 1d); the near-in-plane conformation (Figure 1c) spontaneously changes to the out-of-plane one during the geometry optimization. The general features of the out-of-plane TS conformation found at all three B3LYP/6-31G*, HF/6-31G*, and $\mathrm{HF} / 3-21 \mathrm{G}$ levels are the same, but values of the geometry parameters are somewhat different (see the last three rows in Table 2). In particular, the B3LYP calculations predict an earlier transition state than the HF calculations, as the B3LYP lengths of bonds being formed during the reaction $(\mathrm{C} 1-\mathrm{C} 2$ and $\mathrm{O} 1-$ $\mathrm{H} 1)$ are longer whereas lengths of bonds being broken (O1$\mathrm{C} 2$ and $\mathrm{C} 1-\mathrm{H} 1)$ are shorter. The activation energy appears to be rather sensitive to the level of the final energy calculations (compare columns of Table 4): the values found at the different levels differ by up to $26 \mathrm{kcal} / \mathrm{mol}$. The sensitivity of the activation energy to the level of the geometry optimization is weaker (compare rows of Table 4): up to $12 \mathrm{kcal} / \mathrm{mol}$ for the MP2(FC)/6-31G* single-point energies and within $7 \mathrm{kcal} / \mathrm{mol}$ for others. HF/3-21G final energies are the highest, while final energies found at the correlated levels (MP2/6-31G* and B3LYP/6-31G*) are generally the lowest and close to each other. It is interesting that in general the $\mathrm{HF} / 3-21 \mathrm{G}$ rather than HF/6-31G* geometries yield results closer to those with the B3LYP/6-31G* geometry optimization. The data of Tables 2 and 4 suggest that the general features of the TS for cyclopropane ring closure in zeolites are correctly predicted by the HF calculations, but for more subtle details the use of a correlated level for both the geometry optimization and final energy calculation is preferred.

3.2. Carbon Isotope Scrambling in 2-Propyl Cation. Now the role of the cyclopropane moieties in the zeolite-catalyzed and in the liquid superacid catalyzed reactions of hydrocarbons will be compared. The real skeletal isomerization can occur, however, only in hydrocarbons with more than three carbon atoms (calculations on such a reaction catalyzed by zeolites will be reported elsewhere ${ }^{58}$, while the above discussed cyclopropane formation from the $\mathrm{C}_{3}$ alkoxy can be considered as a part of the carbon isotope scrambling in propane. Therefore it is natural to compare the mechanism of the carbon scrambling in zeolites with the mechanism of this reaction in liquid superacids. According to Haw et al. ${ }^{33}$ the former reaction is not observed at low temperatures when the latter one readily occurs. This indicates that persistent free 2-propyl cation cannot be formed in zeolites. ${ }^{33}$

The carbon isotope scrambling in 2-propyl cation was experimentally studied in the liquid superacid media. ${ }^{61,62}$ Koch et al. have performed the quantum-chemical characterization of the reaction paths for the carbon and hydrogen isotope scrambling in the free 2-propyl cation. ${ }^{63}$ They have found that the hydrogen scrambling proceeds via the transition state having the 1-propyl cation geometry, while the path for the carbon scrambling includes the corner-protonated cyclopropane (local minimum) and another transition state with the 1-propyl cation geometry but different from the TS for the hydrogen scrambling.

Below the most important results of Koch et al. ${ }^{63}$ concerning the carbon scrambling are repeated at several theory levels including the very precise Gaussian-2 (G2) model ${ }^{54}$ and, for a purpose of comparison, three DFT methods. We consider the 2-propyl cation, corner-PCP, edge-PCP, and TS between the 
TABLE 5: Relative Energies of the Free $\mathrm{C}_{3} \mathrm{H}_{7}{ }^{+}$Isomers Calculated at Different Theory Levels (Including Corrections for Zero-Point Energies)

\begin{tabular}{|c|c|c|c|c|c|c|}
\hline structure & $\begin{array}{l}\text { MP4(FC)/6-311G**// } \\
\text { MP2(FU)/6-311G**a }\end{array}$ & Gaussian-2 & MP2(FU)/6-31G* & B3LYP/6-31G* & BLYP/6-31G* & B3P86/6-31G* \\
\hline 2-propyl cation & 0 & 0 & 0 & 0 & 0 & 0 \\
\hline corner-PCP & +7.2 & +7.6 & +6.4 & +12.2 & +12.7 & +10.6 \\
\hline edge-PCP & +8.6 & +8.8 & +9.0 & +16.0 & +17.5 & +12.3 \\
\hline $\begin{array}{l}\text { TS between the 2-propyl } \\
\text { cation and corner-PCP }\end{array}$ & +20.5 & +20.8 & +21.3 & +22.0 & +21.7 & +22.8 \\
\hline
\end{tabular}

2-propyl cation and corner-PCP (structures "2-propyl”, “cornerprotonated I", "edge-protonated", and "1-propyl II", respectively, in Table 1 of the paper of Koch et al. ${ }^{63}$ ). One can see from the data of Table 5 that the $\mathrm{G} 2$ results are very close to the MP4(FC)/6-311G**//MP2(FU)/6-311G** results ${ }^{63}$ (the difference does not exceed $0.4 \mathrm{kcal} / \mathrm{mol})$. The MP2(FU)/6-31G* values are also very close to $\mathrm{G} 2$ (differences are within $1.2 \mathrm{kcal} / \mathrm{mol}$ ). The DFT methods perform rather well although deviation of their results from the $\mathrm{G} 2$ ones is somewhat larger. In particular they predict the relative energy of the corner-PCP to be 3-5 $\mathrm{kcal} / \mathrm{mol}$ higher and that of the edge-PCP to be $3.5-9 \mathrm{kcal} /$ mol higher. It should also be noted that the edge-PCP is a local minimum on the MP2(FU)/6-31G* and MP2(FU)/6-311G**63 potential energy surfaces but is a first-order saddle point according to all three DFT methods, B3LYP, BLYP, and B3P86. The B3P86 method yields the closest to the G2 and MP2 relative energies for the corner- and edge-PCP, the BLYP method is closest for the relative energy of the TS, and the B3LYP method is intermediate for all cases.

The relative energy of the TS is in fact the activation energy for the carbon isotope scrambling in the free 2-propyl cation. However the experimental activation energy for this reaction in the $\mathrm{SO}_{2} \mathrm{FCl}-\mathrm{SbF}_{5}$ superacid solution of $15.7 \mathrm{kcal} / \mathrm{mol}^{21,61}$ is significantly ( $5 \mathrm{kcal} / \mathrm{mol}$ or more) lower than that calculated at all the levels (see Table 5) including the G2 model. A similar discrepancy was found by Koch et al. ${ }^{63}$ between the calculated and measured activation energies for the hydrogen isotope scrambling in the free 2-propyl cation. This is somewhat surprising as the reported ${ }^{50,51} \mathrm{MP} 2$ and DFT activation energies for the three other similar reactions, carbon scrambling in the 2-butyl cation, skeletal isomerization of the 2-butyl cation, and skeletal isomerization of the 2-pentyl cation, are within 1-2 $\mathrm{kcal} / \mathrm{mol}$ from the corresponding experimental values. This suggests that even in the superacid solution the influence of solvation effects on the relative stabilities of the $\mathrm{C}_{3} \mathrm{H}_{7}+$ isomers is not negligible. Although carbocations in liquid superacid media are usually considered as free moieties, several examples of their reactivity modified by solvation are known. For instance solvation effects are reported to change the relative stability of the $t$-butyl and adamantyl cations in superacid media with respect to the gas phase. ${ }^{64}$

The comparison of the reaction paths for carbon isotope scrambling in the adsorbed propyl group and in the free 2-propyl cation is given in Figure 2. The latter reaction (described by Koch et al. ${ }^{63}$; see also Figure $2 \mathrm{~B}$ ) starts with the hydride shift from the methyl group to the secondary carbon. The resulting 1-propyl cation is not a local minimum on the potential energy surface, but represents a transition state for formation of the corner-PCP ion. The negative eigenvalue in this TS is contributed mainly by the rotation around the $\mathrm{C} 2-\mathrm{C} 3$ bond, which moves the $\mathrm{C} 1$ carbon to a position more suitable for bonding to the $\mathrm{C} 3$ carbon. After the corner-PCP is formed its ring is reopened in the different position, preserving the $\mathrm{C} 1-$ $\mathrm{C} 3$ bond and breaking the $\mathrm{C} 1-\mathrm{C} 2$ bond. This yields again the transition state and finally the scrambled 2-propyl cation. Such
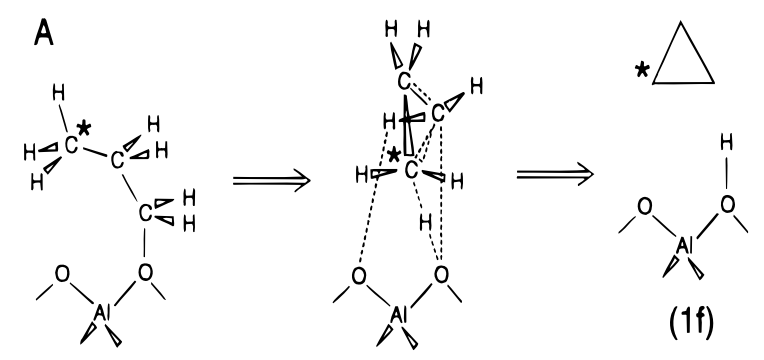

(1b)

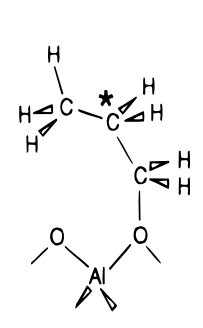

$\left(1 b^{\prime}\right)$
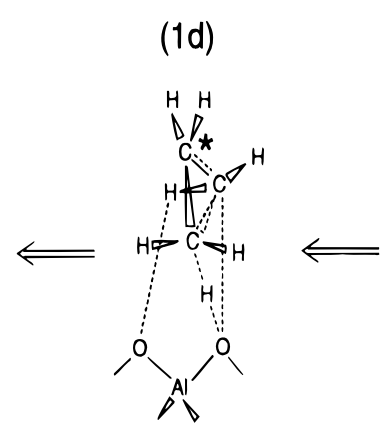

(1d)

(1f)
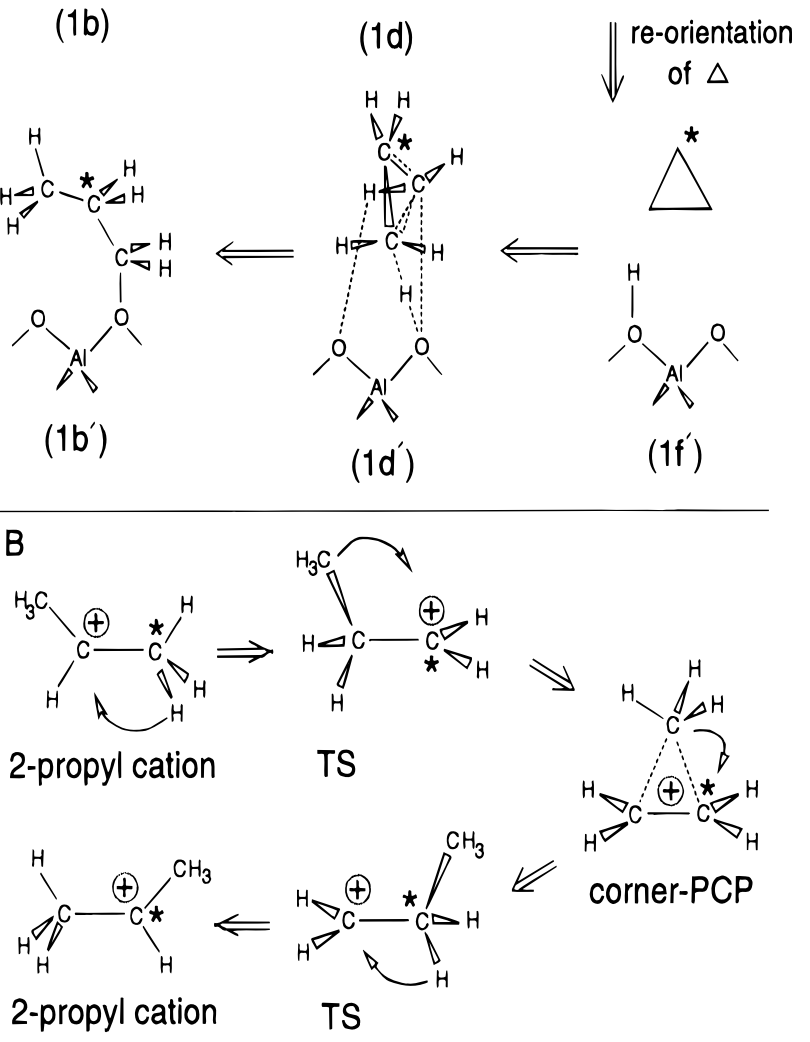

Figure 2. Carbon isotope scrambing: A, in zeolites; B, in liquid superacids. The asterisk marks the ${ }^{13} \mathrm{C}$ atoms.

a reaction path (similar to that suggested for the liquid superacid catalyzed skeletal isomerization of higher alkanes ${ }^{21}$ and that found by quantum-chemical calculations for 2-butyl and 2-pentyl cation isomerization ${ }^{50,51}$ ) starts with the relatively stable carbocations.

In contrast, the isotope scrambling in the adsorbed species starts with the covalent propyl group while the ionic species represent only transition states as shown in Figure 2A. The consequent cyclopropane ring closure, reorientation of the cyclopropane moiety versus the adsorption site, and ring reopening result in formation of the new propyl group with a different isotope distribution. Such a difference in the mechanisms of scrambling in the free propyl cation and in the adsorbed propyl group is consistent with the observations of Haw et al. ${ }^{33}$ that the former reaction does not occur at low temperatures when the latter one readily occurs. 


\section{Conclusion}

Quantum-chemical calculations on mechanisms involving participation of the free and protonated cyclopropane species in the zeolite-catalyzed skeletal isomerization of hydrocarbons as well as in the liquid superacid catalyzed carbon isotope scrambling in propane have been performed. The results obtained indicate that:

1. According to the $\mathrm{B} 3 \mathrm{LYP} / 6-31 \mathrm{G}^{*}$ calculations, formation of cyclopropane from a surface alkoxy species occurs via a transition state whose hydrocarbon part resembles a cornerprotonated cyclopropane ring. Two conformations of such a transition state were found. They differ in the orientation of the PCP portion with respect to the acid site.

2. General features of the TS for cyclopropane ring closure/ opening found in the present work are the same as were calculated earlier at the MP2/6-31G*//3-21G level and with planar symmetry constraints. However the activation energy is found to be significantly lower and thus closer to the available experimental values.

3. The computed activation energies are found to be rather sensitive to the level of final energy calculations and less sensitive to the level of geometry optimization.

4. Structures involved in the carbon isotope scrambling in the 2-propyl cation were calculated at several theory levels up to the G2 model. The relatively stable intermediates of this superacid-catalyzed reaction are carbocations, in contrast to the zeolite-catalyzed reaction where the relatively stable intermediates are surface alkoxy species with the corner-protonated cyclopropane as a high-energy transition state.

Acknowledgment. The financial support of the Dutch Science Foundation program (NWO) is greatly appreciated.

\section{References and Notes} 1992.

(1) Gates, B. C. Catalytic Chemistry; John Wiley and Sons: New York,

(2) Maxwell, I. E.; Stork, W. H. J. In Introduction to Zeolite Science and Practice; van Bekkum, H., Flanigen, E. M., Jansen, J. C., Eds.; Elsevier: Amsterdam, 1991; p 571.

(3) Chevalier, F.; Guisnet, M.; Maurel, R. In Proceedings of the 6th International Congress on Catalysis; Bond, G. C., Wells, P. B., Tompkins, F. C., Eds.; The Chemical Society: London, 1977; p 478.

(4) Weitkamp, J. Ind. Eng. Chem. Prod. Res. Dev. 1982, 21, 550.

(5) Martens, J. A.; Jacobs, P. A. In Theoretical Aspects of Heterogeneous Catalysis; Moffat, J. B., Ed.; Van Nostrand Reinhold: New York, 1990; p 52.

(6) Gao, Z.; Chen, J.-m.; Hua, W.-m.; Tang, Y. Stud. Surf. Sci. Catal. 1994, 90, 507 (Acid-Base Catalysis II).

(7) Liu, H.; Lei, G. D.; Sachtler, W. M. H. Appl. Catal. A 1996, 137, 167.

(8) Bearez, C.; Chevalier, F.; Guisnet, M. React. Kinet. Catal. Lett. 1983, 22, 405.

(9) Krupina, N. N.; Proskurnin, A. L.; Dorogochinskii, A. Z. React. Kinet. Catal. Lett. 1986, 32, 135. 376.

(10) Asuquo, R. A.; Eder-Mirth, G.; Lercher, J. A. J. Catal. 1995, 155,

(11) Chao, K.-j.; Wu, H.-c.; Leu, L.-j. J. Catal. 1995, 157, 289.

(12) Guisnet, M.; Andy, P.; Gnep, N. S.; Benazzi, E.; Travers, C. J. Catal. 1996, 158, 551.

(13) Asensi, M. A.; Corma, A.; Martinez, A. J. Catal. 1996, 158, 561.

(14) Garin, F.; Seyfried, L.; Girard, P.; Maire, G.; Abdulsamad, A.; Sommer, J. J. Catal. 1995, 151, 26.

(15) Adeeva, V.; Lei, G. D.; Sachtler, W. M. H. Appl. Catal. A 1994 118, L11.

(16) Tabora, J. E.; Davis, R. J. J. Catal. 1996, 162, 125.

(17) Xu, W.-Q.; Yin, Y.-G.; Suib, S. L.; Edwards, J. C.; O’Young, C.L. J. Phys. Chem. 1995, 99, 9443.

(18) Meriaudeau, P.; Bacaud, R.; Ngoc Hung, L.; Vu, Anh. T. J. Mol. Catal. 1996, 110, L177.

(19) Guisnet, M.; Andy, P.; Gnep, N. S.; Travers, C.; Benazzi, E. In 11th International Zeolite Conference (Book of Abstracts); Chon, H., Ihm, S.-K., Uh, Y. S., Seo, G., Eds.; 1996; Abstract OB25.

(20) Olah, G. A.; Prakash, G. K. S.; Sommer, J. Superacids; Wiley-Interscience: New York, 1985.
(21) Brouwer, D. M.; Oelderic, J. M. Rec. Trav. Chim. 1968, 87, 721. (22) Brouwer, D. M.; Hogeveen, H. Prog. Phys. Org. Chem. 1972, 9, 179.

(23) Sauer, J.; Ugliengo, P.; Garrone, E.; Saunders, V. R. Chem. Rev. 1994, 94, 2095.

(24) Kramer, G. J.; van Santen, R. A. Chem. Rev. 1995, 95, 637.

(25) Blaszkowski, S. R.; van Santen, R. A. Top. Catal., in press.

(26) Rigby, A. M.; Kramer, G. J.; van Santen, R. A. J. Catal., in press.

(27) Hehre, W. J.; Radom, L.; Schleyer, P. v R.; Pople, J. A. An Initio

Molecular Orbital Theory; John Wiley and Sons: 1986.

(28) Kazansky, V. B. Acc. Chem. Res. 1991, 24, 379.

(29) Kazansky, V. B. Stud. Surf. Sci. Catal. 1994, 85, 251 (Advanced Zeolite Science and Applications, Jansen, J. C., Stoecker, M., Karge, H. G., Weitkamp, J., Eds.; Elsevier, 1994).

(30) Kazansky, V. B.; Senchenya, I. N. J. Catal. 1989, 119, 108.

(31) Aronson, M. T.; Gorte, R. J.; Farneth, W. E.; White, D. J. Am. Chem. Soc. 1989, 111, 840 .

(32) Haw, J. F.; Richardson, B. R.; Oshiro, I. S.; Lado, N. D.; Speed, J. A. J. Am. Chem. Soc. 1989, 111, 2052.

(33) Haw, J. F.; Nicholas, J. B.; Xu, T.; Beck, L. W.; Ferguson, D. B. Acc. Chem. Res. 1996, 29, 259.

(34) Senchenya, I. N.; Kazansky, V. B. Catal. Lett. 1991, 8, 317.

(35) Kramer, G. J.; van Santen, R. A.; Emeis, C. A.; Nowak, A. K. Nature 1993, 363, 529.

(36) Viruela-Martin, P.; Zikovich-Wilson, C. M.; Corma, A. J. Phys. Chem. 1993, 97, 13713 .

(37) Blaszkowski, S. R.; Nascimento, M. A. C.; van Santen, R. A. J. Phys. Chem. 1996, 100, 3463.

(38) Kazansky, V. B.; Frash, M. V.; van Santen, R. A. Appl. Catal. A 1996, 146, 225.

(39) Frisch, M. J.; Trucks, G. W.; Schlegel, H. B.; Gill, P. M. W.; Johnson, B. G.; Robb, M. A.; Cheeseman, J. R.; Keith, T.; Petersson, G. A.; Montgomery, J. A.; Raghavachari, K.; Al-Laham, M. A.; Zakrzewski, V. G.; Ortiz, J. V.; Foresman, J. B.; Cioslowski, J.; Stefanov, B. B.; Nanayakkara, A.; Challacombe, M.; Peng, C. Y.; Ayala, P. Y.; Chen, W.; Wong, M. W.; Andres, J. L.; Replogle, E. S.; Gomperts, R.; Martin, R. L.; Fox, D. J.; Binkley, J. S.; Defrees, D. J.; Baker, J.; Stewart, J. P.; HeadGordon, M.; Gonzalez, C.; Pople, J. A. Gaussian 94, Revision B.3; Gaussian, Inc.: Pittsburgh, PA, 1995.

(40) Carpenter, J. E.; Weinhold, F. J. Mol. Struct. (THEOCHEM) 1988 169,41 .

(41) Glendening, E. D.; Reed, A. E.; Carpenter, J. E.; Weinhold, F. NBO, Version 3.1 .

(42) Evleth, E. M.; Kassab, E.; Jessri, H.; Allavena, M.; Montero, L.; Sierra, L. R. J. Phys. Chem. 1996, 100, 11368.

(43) Blaszkowski, S. R.; van Santen, R. A. J. Am. Chem. Soc. 1996, 118,5152 .

(44) Kramer, G. J.; van Santen, R. A. J. Am. Chem. Soc. 1995, 117, 1766.

(45) (a) Becke, A. D. J. Chem. Phys. 1993, 98, 1372. (b) Becke, A. D. J. Chem. Phys. 1993, 98, 5648.

(46) Lee, C.; Yang, W.; Parr, R. G. Phys. Rev. B 1988, 37, 785

(47) Raghavachari, K.; Whiteside, R. A.; Pople, J. A.; Schleyer, P. v. R. J. Am. Chem. Soc. 1981, 103, 5649.

(48) Carneiro, J. W. de M.; Schleyer, P. v. R.; Saunders, M.; Remington, R.; Schaefer, H. F., III; Rauk, A.; Sorensen, T. S. J. Am. Chem. Soc. 1994, 116,3483 .

(49) Collins, S. J.; O’Malley, P. J. Chem. Phys. Lett. 1994, 228, 246. 633 .

(50) Boronat, M.; Viruela, P.; Corma, A. J. Phys. Chem. 1996, 100,

(51) Boronat, M.; Viruela, P.; Corma, A. J. Phys. Chem. 1996, 100, 16514

(52) Becke, A. D. Phys. Rev. A 1988, 38, 3098.

(53) Perdew, J. P. Phys. Rev. B 1986, 33, 8822.

(54) Curtiss, L. A.; Raghavachari, K.; Trucks, G. W.; Pople, J. A. J. Chem. Phys. 1991, 94, 7221.

(55) Wiberg, K. B.; Kass, S. R. J. Am. Chem. Soc. 1985, 107, 988.

(56) Liu, H.; Lei, G. D.; Sachtler, W. M. H. Appl. Catal. 1996, 137, 167.

(57) Van de Runstraat, A. Adsorption Effects in Acid Catalysis by Zeolites, Ph. D. Thesis, Eindhoven University of Technology, Eindhoven, 1996; p 77.

(58) Rigby, A. M.; Frash, M. V. To be submitted for publication.

(59) Brandt, H. V.; Curtiss, L. A.; Iton, L. E. J. Phys. Chem. 1993, 97 , 12773.

(60) Ramachandran, S.; Lenz, T. G.; Skiff, W. M.; Rappe, A. K. J. Phys. Chem. 1996, 100, 5898 .

(61) Olah, G. A.; White, A. M. J. Am. Chem. Soc. 1969, 91, 5801.

(62) Saunders, M.; Vogel, P.; Hagen, E. L.; Rosenfeld, J. Acc. Chem.

Res. 1973, 6, 53 .

(63) Koch, W.; Liu, B.; Schleyer, P. v. R. J. Am. Chem. Soc. 1989, 111,3479 .

(64) Mirda, D.; Rapp, D.; Kramer; G. M. J. Org. Chem. 1979, 44, 2619. 